\title{
Analisis Unggahan Media Sosial pada Instagram Rachel Vennya Menggunakan Metode Importance Performance*
}

\author{
Else Virdiani ${ }^{1}$, Aam Alamudi $^{2 \ddagger}$, Yenni Angraini ${ }^{3}$ \\ 1PT. MNC Sky Vision, Indonesia \\ ${ }^{23}$ Department of Statistics, IPB University, Indonesia \\ ‡corresponding author: alamudi@apps.ipb.ac.id
}

Copyright ( 2022 Else Virdiani, Aam Alamudi, and Yenni Angraini. This is an open-access article distributed under the Creative Commons Attribution License, which permits unrestricted use, distribution, and reproduction in any medium, provided the original work is properly cited.

\begin{abstract}
Instagram is one of the social media applications that can publish photos or videos for its users. Rachel Vennya is a well-known Instagram user who has more than five million followers. This research was conducted to see the expected posts by Rachel Vennya's followers on Instagram. Through the importance-performance analysis (IPA) it will be known the types of posts that are interesting and need to be increased in publication. This study's two IPA approaches, namely expected performance analysis (EPA) and importance-performance matrix analysis (IPMA). The results of each analysis are then mapped into a Cartesian diagram so that it is known that several posts increase follower loyalty and posts that need to be increased or decreased. After comparing the two Cartesian diagrams, it is known that there is no difference in the placement of variables between the two analyzes. Posts that deserve to be maintained include Motivation, Cooking, Family, and posts considered excessive in the publication are Business and Endorsements. Furthermore, customer satisfaction index (CSI) analysis was carried out to see follower satisfaction. The CSI value obtained is 72.69 , which indicates the follower satisfaction index belongs to the satisfied criteria.
\end{abstract}

Keywords: customer satisfaction index (CSI), importance-performance analysis (IPA), Instagram, Rachel Vennya

\section{Pendahuluan}

Instagram merupakan salah satu aplikasi media sosial untuk berbagi foto/video yang paling banyak digunakan mencapai 1 miliar pengguna dari seluruh dunia $(R$ 2018). Melalui Instagram seseorang dapat mengunggah apapun dan dapat dilihat oleh siapapun. Instagram menjadi tempat yang tepat untuk mempromosikan produk, menampilkan iklan dan informasi produk. Semakin menarik unggahan seseorang semakin banyak pengikut yang didapatkan. Salah satu pengguna Instagram yang menarik dan menginspirasi adalah Rachel Vennya dengan lebih dari 5 juta pengikut terhitung hingga November 2020.

\footnotetext{
* Received: Aug 2021; Reviewed: Sep 2021; Published: Jan 2022
} 
Rachel Vennya (RV) adalah seorang entrepreneur yang menarik, memiliki dua orang anak dengan gaya hidupnya yang mengundang perhatian. Melalui unggahannya tak sedikit yang terpengaruh dengan suatu produk yang la gunakan ataupun untuk sebuah promosi. Kegiatan periklanan yang dilakukan online shop untuk mempromosikan produknya kepada selebriti instagram dikenal dengan istilah Celebrity Endorsement.

Menurut Shimp (2010) celebrity endorsement adalah memanfaatkan seorang artis, entertainer, public figure yang dikenal masyarakat karena kemampuannya di suatu bidang yang dapat mendukung produk yang di promosikannya. Banyak online shop yang berani mengeluarkan biaya yang besar agar dapat mengiklankan produknya kepada RV. Keberanian tersebut diduga karena banyak yang memberikan testimoni setelah beriklan dengan RV.

Iklan yang dilakukan oleh Rachel Vennya untuk mempromosikan sebuah produk, diduga mampu memengaruhi pengikut melalui Instagramnya. Maka dari itu diperlukan sebuah analisis untuk melihat jenis unggahan yang harapkan pengikut berdasarkan kinerja dari publikasi foto atau video di Instagram. Penelitian ini bertujuan untuk melihat jenis unggahan Instagram Rachel Vennya yang diharapkan pengikut dan melihat unggahan yang dapat mempertahankan loyalitas pengikut. Peubah yang digunakan diperoleh dari bentuk unggahan yang dikelompokan kedalam fitur highlight yang ada di Instagram. Data yang digunakan dalam penelitian ini merupakan data primer dari kuesioner.

\section{Metodologi}

\subsection{Data}

Data yang digunakan dalam penelitian ini adalah data primer diambil melalui kuesioner yang disebarkan melalui media sosial dengan ketentuan responden merupakan pengikut Instagram Rachel Vennya yang setidaknya telah mengikuti Instagram Rachel Vennya selama enam bulan terakhir. Kuesioner berisi pertanyaan tertutup dan mengarah kepada peubah yang ditentukan.

\subsection{Prosedur Pengambilan Data}

Data dari penelitian ini didapatkan dengan tahapan sebagai berikut:

A. Rancangan sampel penelitian

1. Teknik sampling yang digunakan yaitu Snowball Sampling.

Menurut Ariestonandri (2006) snowball sampling adalah teknik penentuan contoh yang disiasati dengan mencari contoh yang sesuai dengan kriteria yang telah ditetapkan. Kemudian dari contoh pertama dicari informasi lain untuk mendapatkan contoh kedua yang memiliki kesamaan kriteria

2. Populasi pada penelitian ini adalah pengikut Instagram Rachel Vennya minimal enam bulan terakhir.

3. Responden pada penelitian ini adalah beberapa pengikut Instagram Rachel Vennya minimal enam bulan terakhir

4. Pengambilan data dilakukan dengan penyebaran kuesioner online selama tiga minggu.

B. Pembuatan kuesioner online untuk penelitian pendahuluan.

Tahapan awal yang dilakukan sebelum penelitian yaitu penentuan peubah/atribut.

C. Melakukan uji validitas dan uji reliabilitas 
Uji validitas dan uji reliabilitas diperlukan untuk menyatakan kuesioner dapat digunakan sebagai alat pengumpul data. Jika kuesioner yang digunakan tidak valid atau tidak reliabel maka butir pertanyaan pada kuesioner ditinjau ulang dan diperbaiki hingga kuesioner dinyatakan valid dan reliabel.

1. Uji Validitas

Uji validitas mengacu pada kesesuaian, kebenaran, kebermaknaan yang kegunaannya khusus dibuat berdasarkan data yang dikumpulkan (Fraenkel et al. 2009). Uji validitas dihitung dengan menghitung koefisien korelasi antar subjek pada item pertanyaan dan dibandingkan dengan total nilai untuk setiap peubah. Apabila $r$ hitung $>r$ tabel atau nilai signifikansi $<0,05$ maka peubah tersebut signifikan dan menunjukkan peubah tersebut memiliki konsistensi dan mengukur aspek yang sama. Rumus untuk uji validitas sebagai berikut:

$$
\begin{gathered}
r_{j}=\frac{n \sum_{i=1}^{n} \quad x_{i j} y_{i}-\left(\begin{array}{ll}
\sum_{i=1}^{n} & x_{i j}
\end{array}\right)\left(\begin{array}{ll}
n \\
\sum_{i=1} & y_{i}
\end{array}\right)}{\sqrt{\left\{\begin{array}{lll}
n \sum_{i=1}^{n} \quad x_{i j}{ }^{2}-\left(\sum_{i=1}^{n}\right. & \left.\left.x_{i j}\right)^{2}\right\} \cdot\left\{n \sum_{i=1}^{n} \quad y_{i}{ }^{2}-\left(\sum_{i=1}^{n}\right.\right. & \left.y_{i}\right)^{2}
\end{array}\right\}}} \\
i=1,2, \ldots, n ; j=1,2, \ldots, k
\end{gathered}
$$

Keterangan:

$r_{j}=$ koefisien korelasi skor skala likert jawaban peubah ke-j terhadap total skor skala likert jawaban seluruh peubah

$n$ = banyaknya responden dalam penelitian

$x_{i j}=$ skor skala likert jawaban responden ke- $i$ untuk peubah ke- $j$

$y_{i}=$ total skor skala likert jawaban responden ke- $i$

2. Uji reliabilitas

Uji Reliabilitas digunakan untuk melihat konsistensi sebuah kuesioner. Kuesioner dapat dikatakan reliabel apabila dicobakan secara berulang pada kelompok yang sama akan menghasilkan data yang sama (Sugiyono 2018). Menentukan suatu peubah reliabel atau tidak sebaiknya memiliki nilai $\alpha \geq 0,60$ (Cronbach et al. 2004). Teknik reliabilitas yang digunakan adalah Cronbach Alpha dengan rumus sebagai berikut

Keterangan:

$$
\alpha=\left[\frac{k}{k-1}\right]\left[1-\frac{\sum_{j=1}^{k} s_{j}^{2}}{s^{2}{ }_{\text {tot }}}\right]
$$

$\alpha \quad=$ koefisien reliabilitas $\alpha$

$k \quad=$ banyaknya peubah

$s^{2}{ }_{j} \quad=$ ragam skor skala likert jawaban peubah ke- $j$

$s^{2}{ }_{t o t}=$ ragam total skor skala likert jawaban seluruh peubah

Jika nilai $\alpha$ mendekati 1 maka reliabilitas peubah yang digunakan semakin kuat, sebaliknya jika nilai $\alpha$ mendekati 0 maka reliabilitas peubah tersebut semakin rendah. Apabila nilai $\alpha$ lebih besar dari 0,60 maka reliabilitas kuesioner sudah dapat dikatakan cukup kuat, sebaliknya jika nilai $\alpha$ lebih kecil dari 0,60 maka kuesioner yang digunakan perlu dilakukan perbaikan.

D. Menyusun kuesioner online menggunakan peubah yang valid dan reliabel 


\subsection{Prosedur Analisis Data}

Berikut adalah tahapan yang dilakukan dalam penelitian ini:

3.1 Melakukan analisis deskriptif

Analisis deskriptif adalah analisis yang mengacu pada metode untuk meringkas data yang dikumpulkan dari sampel atau populasi. Ringkasan tersebut biasanya terdiri dari grafik dan angka-angka seperti rata-rata dan persentase (Agresti 2012).

\subsection{Melakukan analisis Importance Performance}

Diagram kartesius akan menunjukkan pandangan pengikut terhadap harapan dan kinerja sebuah unggahan yang paling berpengaruh yang dirata-ratakan dengan jumlah responden kemudian dibuat diagram kartesius dari rata-rata responden.

a. Importance Performance Matrix Analysis (IPMA)

IPMA digunakan untuk memeriksa peubah-peubah yang populer dikalangan konsumen. Menurut Martilla dan James dalam Bruyere et al. (2002) matriks importance-performance terbentuk dari empat kuadran yang masing-masing kuadran menggambarkan pemahaman visual tentang kepuasan konsumen secara keseluruhan. Input dari IPMA adalah jawaban kuesioner yang terdiri dari dua faktor, yaitu faktor kinerja (performance) dan faktor harapan (importance). Hasil IPMA berupa diagram yang memposisikan setiap peubah yang ada di dalam kuesioner yang dipetakan ke dalam diagram kartesius dimana sumbu $X$ adalah faktor kinerja sedangkan sumbu $Y$ adalah faktor harapan

b. Expectation Performance Analysis (EPA)

EPA juga merupakan modifikasi dari importance performance analysis (IPA). Menggunakan analisis ekspektasi (expectation analysis) dapat ditunjukkan korelasi antara harapan dan kinerja sehingga pengkategorian peubah dapat dilakukan dengan mudah. Pendekatan ini membantu pengkategorian peubah yang lebih populer dan tidak populer (Abdar 2020)

\subsection{Analisis Customer Satisfaction Index (CSI)}

CSI merupakan analisis kuantitatif berupa persentase pengguna yang senang dalam suatu survei. Analisis CSI diperlukan untuk mengetahui tingkat kepuasan pengguna secara menyeluruh dengan memperhatikan tingkat kepentingan dari peubah-peubah suatu produk atau jasa. Aritonang (2005) mengelompokkan lima kategori yang digunakan untuk mengukur CSI dimana persentase nilai yang didapatkan sebanding dengan kriteria kepuasan konsumen. Semakin tinggi nilai CSI yang didapatkan maka kepuasan konsumen semakin kuat.

\section{Hasil dan Pembahasan}

\subsection{Penelitian Pendahuluan}

Uji yang digunakan dalam penelitian pendahuluan yaitu uji validitas dan uji reliabilitas. Menurut Samuels (2016) banyaknya responden minimal yang dibutuhkan untuk melakukan uji reliabilitas yaitu 30 responden. Roscoe (1975) 
mengatakan bahwa aturan praktis untuk menentukan ukuran contoh dalam melakukan pengujian terhadap kuesioner setidaknya menggunakan antara 30 sampai dengan 500 responden. Oleh karena itu pada penelitian pendahuluan ini, kuesioner diujicobakan kepada 30 responden.

\subsection{Uji Validitas}

Uji validitas dilakukan dengan mengkorelasikan skor rata-rata jawaban responden masing-masing peubah dengan nilai skor rata-rata total seluruh peubah. Jika nilai korelasinya lebih besar dari nilai $r$ tabel yaitu 0,31 maka peubah tersebut dapat dikatakan valid. Jika nilai korelasi lebih kecil dari nilai $r$ tabel maka peubah tersebut perlu ditinjau ulang. Hasil yang didapatkan dijelaskan oleh Tabel 1.

\begin{tabular}{lc} 
Tabel 1 Hasil uji validitas faktor \\
\hline Peubah & Nilai $r$ \\
\hline Family & 0.80 \\
Holiday & 0.87 \\
Friends & 0.90 \\
Cooking & 0.92 \\
Motivation & 0.85 \\
Romance & 0.74 \\
Endorsement & 0.85 \\
Bussines & 0.71
\end{tabular}

Berdasarkan nilai $r$ yang didapatkan terlihat bahwa nilai korelasi skor rata-rata jawaban setiap peubah terhadap totalnya sudah lebih besar dari nilai $r$ tabel yaitu 0,31 . Hal yang serupa dilakukan terhadap faktor harapan yang dapat dijelaskan oleh Tabel 3.

\begin{tabular}{lc} 
Tabel 3 Hasil uji validitas faktor \\
\hline Peubah & Nilai $r$ \\
\hline Family & 0.89 \\
Holiday & 0.85 \\
Friends & 0.90 \\
Cooking & 0.86 \\
Motivation & 0.88 \\
Romance & 0.77 \\
Endorsement & 0.92 \\
Bussines & 0.94
\end{tabular}

Setelah dilakukan uji validitas pada faktor kinerja, nilai korelasi skor ratarata jawaban setiap peubah terhadap totalnya sudah lebih besar dari nilai $r$ tabel, maka peubah-peubah yang digunakan sudah dapat dikatakan valid.

\subsection{Uji Reliabilitas}

Nilai a pada faktor kinerja yang diperoleh dari rumus a menunjukkan angka 0,95. Merujuk pada Tabel 1 nilai $\alpha$ tersebut sudah dapat dikatakan sangat kuat. Maka dari itu peubah-peubah yang berada pada faktor kinerja sudah dapat dikatakan reliabel. Hal serupa dilakukan pada faktor harapan. Nilai 
Cronbach Alpha yang didapatkan melalui rumus sangat kuat yaitu 0,93. Maka dari itu peubah-peubah yang digunakan pada faktor kinerja sudah dapat digunakan sebagai alat pengumpul data.

\subsection{Karakteristik Responden}

Penyebaran kuesioner penelitian dilakukan selama tiga minggu dan kuesioner disebarkan kepada 217 responden. Kuesioner yang dikembalikan sebanyak 185 responden. Responden yang sesuai dengan kriteria yaitu telah mengikuti Rachel Vennya selama enam bulan terakhir terhitung hingga penelitian dimulai adalah 153 responden. Kriteria responden sebagai berikut:

a. Domisili Responden

Domisili responden dikelompokkan menjadi dua kelompok yaitu wilayah Jabodetabek dan luar Jabodetabek. Kriteria responden yang berdomisili di luar Jabodetabek lebih banyak yaitu sebanyak 87 responden atau sebesar $56,86 \%$ sedangkan responden yang berdomisili di Jabodetabek sebanyak 66 responden atau sebesar $43,13 \%$.

b. Jenis Kelamin

Jenis kelamin responden didominasi oleh perempuan yaitu sebanyak $93 \%$ sedangkan responden berjenis kelamin laki-laki sebanyak $7 \%$. Hal tersebut menyimpulkan bahwa Instagram Rachel Vennya lebih menarik perhatian responden berjenis kelamin perempuan daripada laki-laki.

c. Pemasukan Perbulan

Sebanyak 30 responden memiliki pemasukan perbulan lebih dari Rp.2.000.000,00, responden menjawab memiliki pemasukan perbulan lebih kecil dari Rp. 1.000.000,00 sebanyak 53 responden. Jumlah pemasukan perbulan yang paling banyak dijawab adalah sekitar Rp. 1.000.000,00 hingga Rp. 2.000.000,00.

d. Intensitas Penggunaan Instagram

Intensitas penggunaan Instagram sangat berpengaruh terhadap perhatian responden terhadap Instagram Rachel Vennya. Sebanyak $43 \%$ responden menggunakan Instagram selama tiga hingga empat jam per-hari, sebanyak $21 \%$ responden hanya menggunakan Instagram satu hingga dua jam per-hari, dan 17\% responden menggunakan Instagram lima sampai enam jam perhari, sedangkan responden yang menjawab menggunakan Instagram lebih dari enam jam per-harinya sebesar $19 \%$. Hal ini menyimpulkan bahwa sebagian besar responden menggunakan Instagram lebih dari tiga jam perharinya.

e. Bentuk Perhatian Terhadap Instagram Rachel Vennya

Perbedaan fitur feeds dan instastory yang ada di Instagram di antaranya adalah feeds akan selalu menampilkan unggahan selama waktu yang ditentukan oleh penggunanya. Unggahan di feeds dapat diedit, dihapus, disunting, dan diarsipkan, sedangkan instastory hanya berdurasi 24 jam, tidak bisa diedit namun bisa dihapus. Sebagian besar responden yaitu sebesar $51,63 \%$ menjawab "kadang-kadang melihat unggahan feeds dan instastory Rachel Vennya" dan sebanyak 32,68\% responden menjawab "Saya selalu melihat unggahan feeds dan instastory-nya". Hanya $15,69 \%$ responden yang menjawab "melihat instastory-nya saja". Jika dijumlahkan responden yang menjawab "kadang-kadang" dan "selalu" melihat unggahan feeds dan instastory 
Instagram Rachel Vennya, disimpulkan bahwa lebih dari $84 \%$ responden memberikan perhatian penuh baik kepada unggahan di feeds maupun instastory pada Instagram Rachel Vennya.

\subsection{Importance Performnce Matrix Analysis (IPMA)}

Analisis yang pertama dilakukan yaitu importance Performance Matrix Analysis (IPMA) dengan menjumlahkan responden yang menjawab pertanyaan dikalikan dengan nilai indeks skala likert kuesioner menggunakan rumus nilai indeks kinerja (NIK). Hasil perhitungan NIK masing-masing faktor dijelaskan oleh Tabel 6 dan Tabel 7.

Tabel 6 Nilai indeks harapan faktor kinerja

\begin{tabular}{|c|c|c|c|c|c|c|c|c|c|c|c|c|c|}
\hline $\begin{array}{c}\text { No. } \\
\text { Pertanyaan }\end{array}$ & 1 & 2 & 3 & & 4 & 5 & 6 & 7 & 8 & 9 & 10 & $\begin{array}{l}\text { Banyaknya } \\
\text { responden }\end{array}$ & $\begin{array}{c}\text { Nilai } \\
\text { Indeks } \\
\text { Kinerja }\end{array}$ \\
\hline A11 & 0 & 0 & 1 & & 4 & 4 & 15 & 29 & 45 & 36 & 19 & 153 & 7,88 \\
\hline A12 & 0 & 0 & 2 & tat & 1 & 7 & 15 & 26 & 44 & 36 & 22 & 153 & 7,92 \\
\hline $\begin{array}{c}\cdots \\
\mathrm{H} 13\end{array}$ & 5 & 5 & 16 & & 8 & 21 & 14 & 34 & 22 & 20 & 8 & 153 & $\begin{array}{c}\cdots \\
6,2614\end{array}$ \\
\hline \multicolumn{14}{|c|}{ Tabel 7 Nilai indeks kinerja faktor harapan } \\
\hline $\begin{array}{c}\text { No. } \\
\text { Pertanyaan }\end{array}$ & 1 & 2 & 3 & 4 & 5 & 6 & 7 & 8 & 9 & 10 & & $\begin{array}{l}\text { nyaknya } \\
\text { sponden }\end{array}$ & $\begin{array}{c}\text { Nilai Indeks } \\
\text { Kinerja }\end{array}$ \\
\hline A21 & 0 & 1 & 3 & 2 & 6 & 13 & 19 & 43 & 37 & 29 & & 153 & 8,01 \\
\hline$A 22$ & 0 & 2 & 1 & 6 & 10 & 22 & 40 & 37 & 24 & 11 & & 153 & 7,28 \\
\hline$\ldots$ & & & & & & & & & & & & & $\ldots$ \\
\hline $\mathrm{H} 21$ & 0 & 0 & 0 & 4 & 8 & 12 & 16 & 49 & 37 & 27 & & 153 & 8,07 \\
\hline
\end{tabular}

Nilai NIK masing-masing faktor kemudian dirata-ratakan perpeubah, sehingga skor rata-rata setiap peubah dapat dipetakan ke dalam diagram kartesius. Diagram kartesius ini dibagi menjadi empat kuadran dengan garis tengah sebagai pembagi kuadran. Nilai rata-rata setiap peubah untuk masingmasing faktor dapat dilihat pada Tabel 8 .

\begin{tabular}{|c|c|c|}
\hline Peubah & NIK $K_{\text {importance }}$ & NIK $K_{\text {performance }}$ \\
\hline Family & 7.74 & 7.42 \\
\hline Holiday & 7.77 & 7.25 \\
\hline Friends & 7.16 & 6.93 \\
\hline Cooking & 8.09 & 7.62 \\
\hline Motivation & 8.11 & 7.38 \\
\hline Romance & 7.67 & 6.17 \\
\hline Endorsement & 5.98 & 7.46 \\
\hline Business & 6.00 & 8.07 \\
\hline
\end{tabular}

Penentuan garis tengah pada diagram importance performance matrix dilakukan dengan menghitung rata-rata semua peubah untuk faktor harapan (importance) maupun faktor kinerja (performance). Hasil perhitungan rata-rata untuk garis tengah pembagi diagram pada faktor kinerja sebagai berikut: 


$$
\overline{\bar{x}}=\frac{58,30}{8}=7,29
$$

Sedangkan perhitungan rata-rata untuk garis tengah pembagi kuadran pada faktor harapan sebagai berikut:

$$
\overline{\bar{x}}=\frac{58,50}{8}=7,31
$$

Hasil perhitungan tersebut kemudian dipetakan ke dalam diagram kartesius sebagaimana dijelaskan pada Gambar 4.

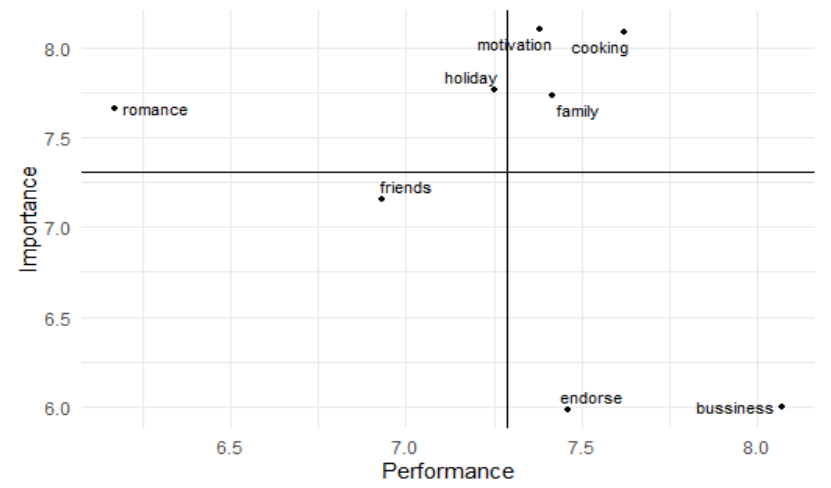

Gambar 4 Importance performance matrix diagram

Kemudian dilakukan EPA dengan merata-ratakan skor skala likert jawaban responden per peubah dan skor tersebut ditempatkan pada diagramkartesius. Nilai rata-rata setiap peubah ditunjukkan oleh Tabel 9.

Tabel 9 Skor rata-rata jawaban EPA

\begin{tabular}{lcc}
\hline \multicolumn{1}{c}{ Peubah } & Expected & Performance \\
\hline Family & 7.75 & 7.13 \\
Holiday & 7.78 & 7.03 \\
Friends & 7.17 & 6.94 \\
Cooking & 8.08 & 7.63 \\
Motivation & 8.12 & 7.40 \\
Romance & 7.69 & 6.18 \\
Endorsement & 5.99 & 7.45 \\
Business & 5.98 & 8.07 \\
\hline
\end{tabular}

Penentuan garis tengah pada diagram EPA dilakukan dengan menghitung rata-rata semua peubah untuk indeks harapan (expected) dan untuk indeks kinerja (performance). Hasil perhitungan rata-rata untuk garis tengah pembagi diagram faktor kinerja sebagai berikut:

$$
\overline{\bar{x}}=\frac{58,55}{8}=7,32
$$

Sedangkan perhitungan rata-rata untuk garis tengah pembagi kuadran pada faktor harapan sebagai berikut:

$$
\overline{\bar{x}}=\frac{57,85}{8}=7,23
$$

Nilai masing-masing peubah dipetakan ke dalam diagram kartesius dengan garis tengah sebagai pembagi diagram. Gambar 5 menunjukkan diagram kartesius expected performance diagram. 


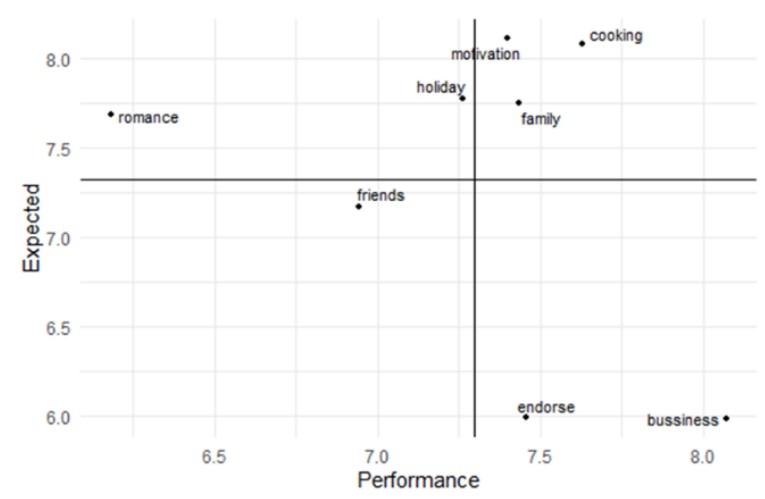

Gambar 5 Expected performance diagram

Hasil analisis tersebut menyimpulkan bahwa tidak terdapat perbedaan penempatan peubah antara analisis EPA dengan IPMA. Dapat dilihat pada masing-masing diagram peubah yang berada di kuadran I menunjukkan prioritas utama untuk dilakukan perbaikan. Peubah yang berada di kuadran tersebut adalah Holiday dan Romance, dimana pengikut menyukai unggahan mengenai liburan dan asmara nya namun unggahan berupa peubah ini jarang dipublikasikan, sehingga perlu dilakukan peningkatan sehingga informasi yang diinginkan oleh pengikut dapat ditangkap dengan baik.

Peubah yang berada pada kuadran II adalah peubah Family, Motivation dan Cooking. Kedua diagram menggambarkan bahwa pengikut Rachel Vennya menyukai unggahan mengenai keluarga, masakan dan beberapa motivasi kutipan dari fitur Question and Answer di Instagram dan performanya sudah baik. Unggahan berupa peubah ini harus dipertahankan untuk menjaga loyalitas dari pengikut Instagram Rachel Vennya.

Kuadran III pada masing-masing diagram menunjukkan peubah yang dianggap pengikut tidak penting dan performa-nya juga tidak terlalu bagus. Peubah ini adalah Friends, artinya pengikut tidak terlalu menginginkan unggahan mengenai teman-temannya. Jika ingin meningkatkan peubah ini perlu ditinjau ulang karena manfaat yang dirasakan oleh pengikut kecil.

Sedangkan pada Kuadran IV kedua diagram menunjukkan peubah yang terlalu berlebihan dirasakan oleh pengikut, yaitu unggahan berupa Endorse dan Business.

Hasil analisis menggunakan EPA dan IPMA memetakan masing-masing peubah kedalam kuadran yang sama, sehingga dapat disimpulkan bahwa menggunakan importance performance analysis dengan pendekatan expected performance analysis (EPA) dan importance performance matrix analysis (IPMA) akan memetakan peubah ke dalam kuadran yang sama.

\subsection{Customer Satisfaction Index (CSI)}

Nilai CSI didapatkan dengan menjumlahkan semua skor rata-rata faktor harapan dari setiap peubah kemudian menghitung WIS masing-masing peubah yaitu proporsi dari skor rata-rata faktor harapan dengan total skor rata-rata faktor harapan. Nilai WSS setipa peubah didapatkan dengan mengalikan skor rata-rata faktor kinerja dengan WIS setiap peubah, sehingga nilai CSI dapat ditunjukkan dengan menjumlahkan semua WSS kemudian dibagi dengan skala likert kuesioner tertinggi yaitu 10 dan dikalikan dengan 100\%. Hasil perhitungan CSI ditunjukkan oleh Tabel 10. 
Tabel 10 Perhitungan nilai CSI

\begin{tabular}{lcccc}
\hline \multicolumn{1}{c}{ Peubah } & Importance & Performance & $\begin{array}{c}\text { Weighted } \\
\text { Importance } \\
\text { Score }\end{array}$ & $\begin{array}{c}\text { Weighted } \\
\text { Satisfaction } \\
\text { Score }\end{array}$ \\
\hline Family & 7,74 & 7,42 & 0,13 & 0,98 \\
Holiday & 7,77 & 7,25 & 0,13 & 0,97 \\
Friends & 7,06 & 6,93 & 0,12 & 0,84 \\
Cooking & 8,09 & 7,62 & 0,14 & 1,06 \\
Motivation & 8,11 & 7,38 & 0,14 & 1,03 \\
Romance & 7,57 & 6,17 & 0,13 & 0,80 \\
Endorsement & 5,98 & 7,46 & 0,10 & 0,77 \\
Business & 6,00 & 8,07 & 0,10 & 0,83 \\
\hline Total & 58,31 & & & 7,27 \\
\hline
\end{tabular}

Nilai total WSS yang dibagi dengan 10 dan dikalikan 100 persen menghasilkan nilai CSI sebesar 72,7 persen dan berada pada rentang 0,610,80 . Hal tersebut menunjukkan bahwa indeks kepuasan pengikut berada pada kriteria puas. Nilai yang didapatkan mengindikasikan bahwa masih ada 27,3 persen pengikut yang belum mampu dipuaskan sepenuhnya oleh unggahan Instagram Rachel Vennya.

\section{Simpulan}

Simpulan yang didapat dalam penelitian ini adalah:

1. Unggahan yang harus dipertahankan adalah unggahan dalam bentuk keluarga, kalimat-kalimat motivasi dan memasak, sedangkan unggahan yang perlu dipertimbangkan dalam melakukan perbaikan adalah unggahan dalam bentuk peubah Friends yang dipublikasikan karena dirasa tidak perlu oleh pengikut dan performanya yang tidak terlalu bagus.

2. Promosi yang dilakukan Rachel Vennya terhadap produk endorsement maupun bisnis yang dimilikinya dianggap berlebihan.

3. Metode expected performance analysis dengan importance performance matrix analysis dapat digunakan untuk analisis unggahan Instagram.

\section{Daftar Pustaka}

Abdar M, Yen NY. 2020. Analysis of user preference and expectation on shared economy platform: an examination of correlation between points of interest on airbnb. Comput Human Behav. 107. doi:10.1016/j.chb.2018.09.039.

Agresti A, Franklin C, Klingenberg B. 2018. Statistics: The Art and Science of Learning from Data, Fourth Edition. Harlow (UK): Pearson Education Limited. Aritonang L. 2005. Kepuasan Pelanggan. Jakarta: Gramedia.

Bhote K. 1996. Beyond Customer Satisfaction to Customer Loyality: The Key to Great Profitability. New York: AMA Membership Publications Division, American Management Association.

Bruyere BL, Rodriguez DA, Vaske JJ. 2002. Enhancing importance-performance analysis through segmentation. J Travel Tour Mark. 12(1):81-95. doi:10.1300/J073v12n01_05. 
Cramer D. 1998. Fundamental Statistics for Social Research. London: Routledge. Cronbach L. 2004. Coefficient alpha and the internal structure of tests.

Psychometrika. 16:297-334.

Fraenkel, Jack R., Wallen NE. 2009. How to Design and Evaluate Research in

Education. New York: the McGraw-Hill Companies, Inc.

Jeko. 2018. Instagram Kantongi 1 Miliar Pengguna di Seluruh Dunia. Liputan6.com., siap terbit. [diakses 2021 Agu 4].

https://www.liputan6.com/tekno/read/3564956/instagram-kantongi-1-miliarpengguna-di-seluruh-dunia.

Joshi A, Kale S, Chandel S, Pal D. 2015. Likert scale: explored and explained. Br J Appl Sci Technol. 7(4):396-403. doi:10.9734/bjast/2015/14975.

Nasrullah R. 2015. Media Sosial: Perspektif Komunikasi, Budaya dan Sosioteknologi. Jakarta: Simbiosa Rekatama Media.

Prajogo DI, McDermott P. 2011. Examining competitive priorities and competitive advantage in service organisations using importance-performance analysis matrix. Manag Serv Qual. 21(5):465-483. doi:10.1108/09604521111159780.

Rangkuti F. 2006. Measuring Customer Satisfaction. Jakarta: PT. Gramedia Pustaka Utama.

Roscoe JT. 1975. Fundamental research statistics for the behavioral sciences. New York: Holt.

Rossiter, John LP. 1998. Advertising and Promotion Manajemen. New York: GrawHill Inc.

Samuels P. 2016. Advice on Reliability Analysis with Small Samples Statistical Methods. Cent Acad Success.

Shimp T. 2010. Advertising Promotion and Other Aspects of Integrated Marketing Communications. South Western: College Publication.

Siyamto. 2017. Pelayanan Bank dengan Menggunakan Metode Importance Performance Analysis (IPA) dan Customer Satisfaction Index (CSI) terhadap Kepuasan Nasabah. Surakarta: STIE-AAS.

Sugiyono. 2009. Statistik untuk Penelitian. Bandung: Alfabeta.

Sugiyono. 2018. Metode Penelitian Kuantitatif, Kualitatif, dan R\&D. Bandung: Alfabeta.

Vogt W, Johnson R. 2012. Correlation and Regression Analysis. London: SAGE Publications Ltd. 